\title{
Reflexões Sobre A Aprendizagem Das Operações Aritméticas Elementares Por Alunos Das Séries Iniciais Do Ensino Fundamental À Luz Da Teoria Dos Campos Conceituais De Gérard Vergnaud ${ }^{1}$
}

\author{
Reflections On The Learning Of Elementary Arithmetic Operations By Elementary \\ School Students In Light Of The Conceptual Field Theory Of Gérard Vergnaud
}

\author{
Célia Finck Brandt* \\ Universidade Estadual de Ponta Grossa - (UEPG) \\ Ettiène Guérios ** \\ Universidade Federal do Paraná - (UFPR) \\ Jane Eletra Serafini Daniel ${ }^{* * *}$ \\ Rede Estadual de Ensino do Paraná, Brasil \\ Ana Lúcia Pereira ${ }^{* * * *}$ \\ Universidade Estadual de Ponta Grossa - (UEPG)
}

\begin{abstract}
Resumo
Neste artigo apresentamos reflexões sobre dificuldades reveladas por alunos do $5^{\circ}$ ano do Ensino Fundamental em cálculos que envolvem as operações de adição, subtração, multiplicação e divisão. Essas dificuldades foram identificadas por meio da análise dos erros dos alunos na resolução de atividades (envolvendo contas e problemas) que foram analisadas à luz dos campos conceituais de Gérard Vergnaud. As resoluções dos alunos revelam que há erros procedimentais e conceituais oriundos de teoremas ou conceitos em ato utilizados na resolução. E que existem erros que comprometem a compreensão de elementos estruturantes do pensamento matemático e que repercutem na dificuldade em resolver os algoritmos convencionais. Esses resultados revelam que a aprendizagem matemática apresentada por alunos ao final dos anos iniciais é frágil e preocupante exigindo ações voltadas para a

\footnotetext{
${ }^{1}$ Este artigo é uma nova leitura à luz da Teoria dos Campos Conceituais de Gérad Vergnaud do artigo denominado "Entre erros e acertos: revelações sobre a aprendizagem das Operações Aritméticas Elementares de alunos dos anos iniciais do Ensino Fundamental" de Guérios e Daniel (2015) originalmente publicado na revista REMATEC/ANO 10/ n. 20/ set. - dez. 2015, p. 6- 20.

* Doutora em Educação Científica e Tecnológica (UFSC). Professora da Universidade Estadual de Ponta Grossa. (UEPG). Ponta Grossa, Paraná, Brasil. brandt@bighost.com.br

** Doutora em Educação Matemática (UNICAMP). Professora da Universidade Federal do Paraná. (UFPR). Curitiba, Paraná, Brasil. ettiene@ufpr.br.

*** Mestre em Educação (UFPR). Professora da Rede Estadual de Ensino do Paraná. Curitiba, Paraná, Brasil. jane.eletra@gmail.com.

**** Doutora em Ensino de Ciências e Educação Matemática - (UEL). Professora da Universidade Estadual de Ponta Grossa - (UEPG). Ponta Grossa, Paraná, Brasil. anabaccon@uepg.br. Bolsista Produtividade da Fundação Araucária.
} 
aprendizagem de conceitos e teoremas presentes na estrutura do sistema de numeração e nas operações. Palavras-chave: Erros em matemática, Matemática anos iniciais, Dificuldade cálculo.

\begin{abstract}
In this article we present reflections on difficulties revealed by students of the 5th year of elementary school in calculations involving addition, subtraction, multiplication and division operations. These difficulties were identified through the analysis of students' errors in solving activities (involving accounts and problems) that were analyzed in light of the conceptual fields of Gérard Verganaud. Student resolutions reveal that there are procedural and conceptual errors arising from concepts used in the resolution. And that there are errors that compromise the understanding of structuring elements of mathematical thinking and that affect the difficulty in solving conventional algorithms. These results reveal that the mathematical learning presented by students at the end of the initial years is fragile and worrying demanding actions directed to the learning of concepts and theorems present in the structure of the numbering system and in operations.
\end{abstract}

Keywords/Palabras clave: Errors in mathematic, Mathematical primary school, Difficulty calculation, Mathematic

\title{
1 Introdução
}

Esse artigo apresenta um estudo reflexivo sobre os resultados obtidos em uma investigação realizada por Guérios e Daniel (2015) acerca de dificuldades na aprendizagem das operações aritméticas elementares de alunos no final do $5^{\circ}$ ano do Ensino Fundamental.

Entre as motivações para a realização deste artigo está a clássica afirmação de que dificuldades de aprendizagem apresentadas por alunos da Educação Básica tem origem nos primeiros anos escolares, focando entre elas, os erros que cometem nas atividades com os algoritmos convencionais, as contas armadas, das operações matemáticas elementares.

Outra motivação está na diversidade de problemas, impasses, dilemas e pontos de tensão na formação inicial de professores da Educação Básica no Brasil evidenciados por Mindal e Guérios (2013) e nas características e problemas dessa formação apresentados por Gatti (2010, 2013).

Daí o interesse em refletir sobre os resultados da investigação realizada por Guérios e Daniel (2015) que analisaram os procedimentos algorítmicos dos alunos e discutiram sobre a aprendizagem dos conteúdos curriculares nas perspectivas conceitual e procedimental. Refletir sobre tais resultados à luz da teoria dos campos conceituais de Gérard Vergnaud, em especial os teoremas e conceitos em ato revelados, constituiu-se em desafio que estas autoras se propuseram a realizar. 


\section{Antecedentes: a pesquisa primeira}

Guérios e Daniel (2015) caracterizaram sua pesquisa como qualitativa, longitudinal com perspectiva analítica relacional, na qual se propuseram a identificar dificuldades que os alunos revelam ter ao final do Ensino Fundamental Anos Iniciais, especificamente, no $5^{\circ}$ ano. Longitudinal, porque acompanharam os alunos no $4^{\circ}$ e no $5^{\circ}$ ano. Relacional, porque analisaram os dados produzidos pelos alunos ao final do $5^{\circ}$ ano nas diferentes atividades desenvolvidas, relacionando-as, considerando os respectivos percursos no $4^{\circ}$ ano. As autoras tiveram como pressupostos: que resolução correta de contas armadas não significa aprendizagem matemática, se estiver reduzida a seu aspecto resolutivo de modo mecânico, sem compreensão conceitual; que o desenvolvimento do pensamento aditivo e do multiplicativo é prioridade para efetivação de uma aprendizagem conceitual das operações aritméticas elementares; e que "a compreensão dos processos resolutivos dos cálculos algorítmicos é constitutiva dessa aprendizagem" (Guérios \& Daniel, 2015, p.7).

Os participantes da pesquisa de Guérios e Daniel (2015) foram 25 alunos do $4^{\circ}$ ano do Ensino Fundamental de uma escola pública do município de Curitiba, Estado do Paraná, no ano de 2013 e os que permaneceram no $5^{\circ}$ ano em 2014, configurando duas fases de produção de dados, uma em cada ano. Todos os alunos dessas turmas participaram das atividades, pois os instrumentos foram aplicados em sala de aula regular. Tendo em vista o objetivo de que as dificuldades fossem identificadas pelos erros cometidos longitudinalmente, foram considerados na análise qualitativa os 12 alunos que participaram de todas as atividades nos anos de $2013 \mathrm{e}$ 2014. Guérios e Daniel justificam que assim fizeram para relacionar os procedimentos realizados pelos alunos nas diferentes atividades e nos diferentes tempos e analisar os erros ocorridos (Guérios \& Daniel, 2015, p. 8).

Foram dois os instrumentos para a produção dos dados empíricos. O primeiro foi composto por 19 contas armadas contemplando as quatro operações aritméticas elementares, organizadas em duas listas de exercícios, uma com dez contas armadas e outro com nove. $\mathrm{O}$ objetivo foi analisar os erros e os acertos realizados pelos alunos, dedicando atenção para suas tentativas, por entenderem que nas tentativas residem indícios do pensamento dos alunos. A primeira aplicação desse instrumento ocorreu quando os alunos estavam no $4^{\circ}$ ano do Ensino Fundamental e a segunda quando estavam no $5^{\circ}$ ano do Ensino Fundamental.

Guérios e Daniel (2015, p.8) analisaram o conhecimento procedimental do aluno, se vinculado ou não ao desenvolvimento do pensamento aritmético aditivo ou multiplicativo, ou 
seja, como resolvem as contas armadas, se as resolvem porque mecanizaram seu procedimento algorítmico ou se atribuem significado matemático às contas armadas que resolvem. No presente artigo, refletimos sobre esse significado à luz da teoria dos campos conceituais de Gérard Vergnaud, em relação à conceitos e teoremas em ato utilizados.

Da primeira lista de atividades do instrumento constaram as seguintes contas armadas:

a) adição de dezenas e unidade, sendo a primeira parcela formada de dezenas e a segunda de unidades, sem reagrupamento $(73+4)$;

b) subtração de dezenas, com minuendo e subtraendo envolvendo dezenas, sem recurso $(68-24)$;

c) adição de centenas e dezenas, sendo a primeira parcela envolvendo centenas e a segunda parcela envolvendo dezenas, sem reagrupamento $(238+61)$;

d) subtração envolvendo dezenas e unidades, sendo o minuendo formado por dezenas e o subtraendo formado por unidades, sem envolver empréstimo $(86-4)$;

e) adição de dezenas com reagrupamento da ordem da dezena para a ordem da centena $(93+16)$

f) subtração envolvendo centenas e dezenas, sendo o minuendo formado por centenas e o subtraendo formado por dezenas, sem reagrupamento $(869-46)$;

g) multiplicação entre dezenas e unidades, sendo o multiplicando formado por dezenas e o multiplicador formado por unidade com reagrupamento da ordem das unidades e das dezenas $(77$ x 8);

h) multiplicação entre centenas e unidades sendo o multiplicando formado por centenas e o multiplicador formado por unidade com reagrupamento da ordem das unidades, das dezenas e das centenas (567 x 6);

i) divisão de dezenas por unidades, formada por dezenas no dividendo e unidades no divisor (86/4);

j) Divisão de centenas por unidades, formada por centenas no dividendo e unidades no divisor (963/3) (Guérios \& Daniel, 2015, p. 8-9).

Da segunda lista de atividades do instrumento constaram as seguintes contas armadas:

a) adição de dezenas e unidades, sendo a primeira parcela formada por dezenas e a segunda parcela formada por unidades, com reagrupamento $(78+6)$;

b) adição de dezenas, sendo a primeira e a segunda parcelas formadas por dezenas, com reagrupamento $(67+23)$;

c) subtração de centenas com recurso da ordem da unidade para a ordem da dezena (345 - 126);

d) subtração de dezenas, com recurso da ordem da unidade para a ordem da dezena ( 85 - 76);

e) adição de centenas com reagrupamentos sucessivos da ordem das unidades para dezenas e da ordem das dezenas para centenas $(567+238)$;

f) multiplicação entre dezenas ( 74 x 36);

g) multiplicação entre centenas e dezenas, sendo o multiplicando formado por centenas e o multiplicador formado por dezenas ( $786 \times 34)$;

h) divisão entre dezenas, sendo o dividendo e o divisor formado por dezenas (99/16); i) divisão envolvendo centenas e dezenas, sendo o dividendo formado por centenas e o divisor formado por dezenas (864/12) (Guérios \& Daniel, 2015, p. 9). 
O segundo instrumento, foi composto por seis contas armadas componentes do primeiro instrumento para as quais foram elaborados enunciados de problemas que contemplavam situações vividas pelos alunos. O objetivo foi verificar se os alunos identificavam a operação matemática que as resolveria. As contas armadas foram:

(68-24) e (869-46) da primeira atividade e (567+238), (345-126), (74x36) e (864/12) da segunda atividade, contemplando subtração de dezenas, subtração de centenas e dezenas, adição de centenas, subtração de centenas, multiplicação envolvendo dezenas e divisão envolvendo centenas e dezenas (Guérios \& Daniel, 2015, p. 9).

Inicialmente, as soluções do primeiro instrumento aplicado em 2013 e 2014 foram organizados em quadros de modo a oferecer um panorama individual dos erros e acertos de todos os alunos de ambos os anos. A seguir, as resoluções dos 12 alunos que realizaram todas as atividades foram analisadas qualitativamente, considerando-se os erros, os acertos e as tentativas de resolução. Por fim, Guérios e Daniel (2015) realizaram análise relacional entre as soluções das seis contas armadas e as soluções dos problemas que as envolviam. Por meio desses procedimentos de análise, as autoras identificaram se "os alunos apresentavam os mesmos ou diferentes erros e se estes erros evidenciavam dificuldades na compreensão matemática das operações aritméticas elementares" (Guérios \& Daniel, 2015, p. 10). Sob o ponto de vista de que o erro pode constituir-se em possibilidade de aprendizagem, as autoras inspiraram-se na afirmação de Cury (2007) de que assim considerá-los pode possibilitar ao professor dinamizar sua aula e na de Guérios (2002) que tal dinamização pode criar um movimento em função dos processos do aprender, que são individuais.

\section{Reflexões À Luz Da Teoria Dos Campos Conceituais De Gérard Vergnaud}

Passamos agora a refletir aobre as produções matemáticas da pesquisa de Guérios e Daniel (2015) à luz da teoria de campos conceituais de Gérard Vergnaud por possibilitar a análise dos procedimentos de resolução de questões de matemática, explicitando as significações compreendidas nos esquemas de pensamento utilizados pelos alunos e subsidiada por uma teoria de conhecimento na dimensão epistemológica e psicológica. Essa referência de análise permitiu apontar as formas de pensar dos alunos, quando explicitadas, ou inferir sobre elas, quando não explicitadas.

Segundo Vergnaud (1990, p. 155), a teoria dos campos conceituais trabalha com a idéia 
de situação e da ação dos sujeitos nestas situações. $\mathrm{O}$ autor reconhece a importância da teoria de Piaget para a teoria dos campos conceituais na qual destaca dois conceitos: o conceito de esquema (organização invariante da conduta para uma dada classe de situações) e de invariante operatório.

Os erros foram analisados em relação aos esquemas que, segundo o autor, permitem investigar os conhecimentos em ação do sujeito, especificamente em relação às categorias de elementos: metas e antecipações, regras de ação, invariantes operatórios (conceitos e teoremas em ato) e possibilidades de inferência em situação.

Para explicar os diferentes tipos de erros apresentados, as hipóteses levantadas, os conceitos não construídos e as significações atribuídas às diferentes soluções, apresentamos as análises dos procedimentos de resolução.

\subsection{Análise De Alguns Dados Empíricos (Algoritmos Convencionais E Contas Armadas)}

A seguir apresentamos em quadros os extratos da pesquisa de Guérios e Daniel (2015) sobre a aprendizagem das operações aritméticas elementares seguidos de reflexão à luz da teoria dos campos conceituais de Gérard Vergnaud. Para facilitar a visualização dos procedimentos relatados, apresentamos alguns procedimentos realizados pelos alunos. Tendo em vista que a reflexão se dá sobre extratos, optanos por apresentar exemplos independentemente de quem o realizou.

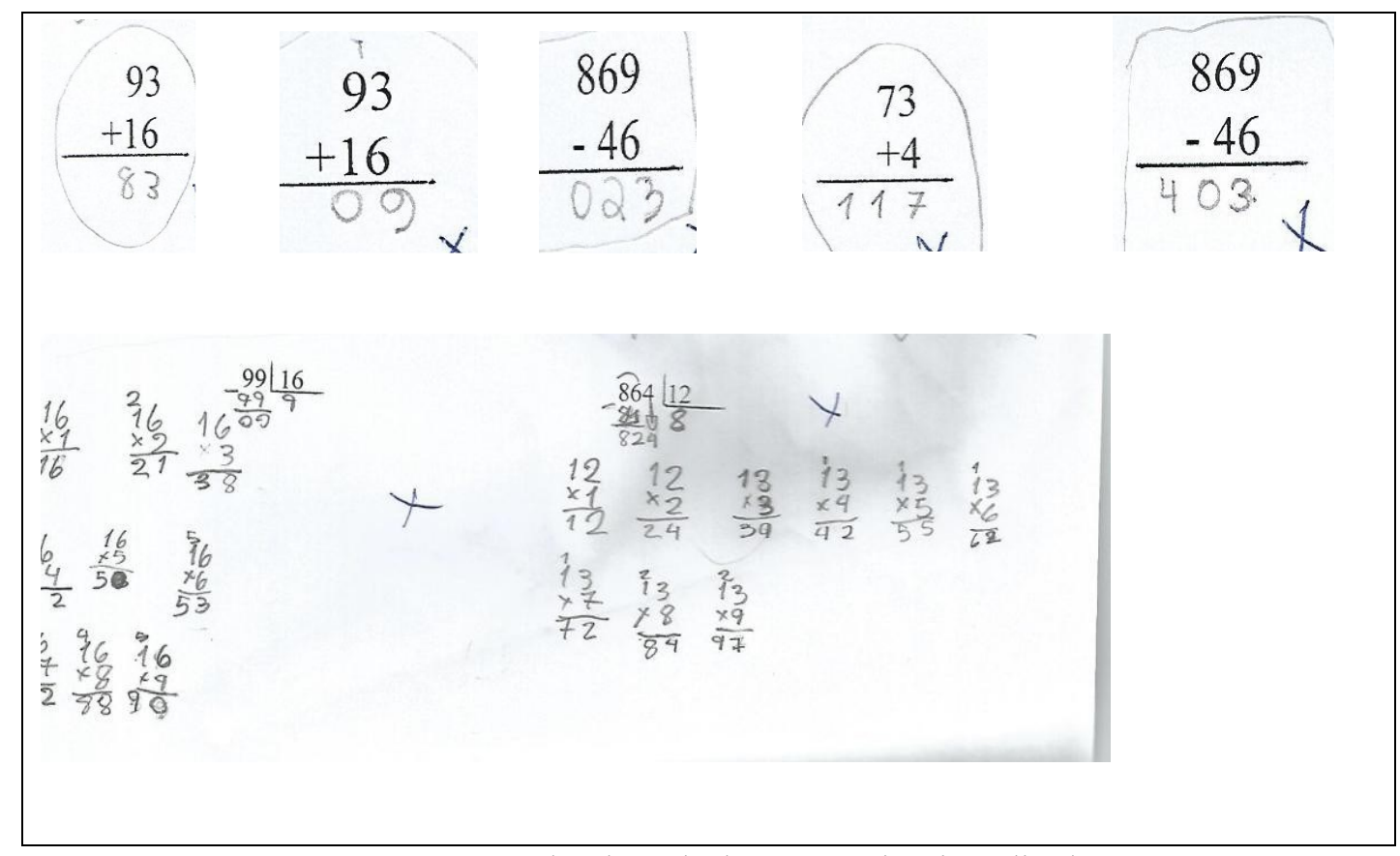

Figura 1: Exemplos dos cálculos convencionais realizados Fonte: Daniel (2015) 
A primeira reflexão refere-se as contas armadas para os cálculos $(93+16=83)$ e $(93+$ $16=09)$.

Quadro 1: Os cálculos $(93+16=83)$ e $(93+16=09)$

Um tipo de erro identificado foi a não compreensão do significado dos sinais de cálculo. $\mathrm{O}$ aluno subtraiu os valores relativos à adição proposta. Aqui, subtraiu o valor maior do menor independente de qualquer outro raciocínio. Efetuou $(6-3=3)$ e $(9-1=8)$. Este erro, em si, pode ser confundido com distração (trocas a operação de adição pela operação de subtração). No entanto, identificamos que há alunos que erram não por distração, mas por ausência de compreensão sobre o que estão efetuando e sobre as próprias operações matemáticas. Esta ausência de compreensão está no fato de que o aluno realiza uma operação de adição e o resultado que obtém é menor do que o valor da primeira parcela, e ele não percebe a inconsistência da resposta obtida. Por óbvio, na adição (93 + 16) o resultado obtido não pode ser menor que 93 , fato não levado em conta pelo aluno ao encontrar 83. Esta inconsistência ocorreu em diferentes resoluções de diferentes alunos, o que nos chamou a atenção, sendo esta apenas um exemplo. Poderíamos interpretar que o aluno se distraiu e realizou uma subtração em vez da adição solicitada $(93-16=63)$, o que não se verifica, pois o resultado de (93-16) é 77. A frequência desse erro deve ser focalizada com atenção porque revela, de fato, não compreensão do processo resolutivo procedimental dos algoritmos das operações, tampouco da ideia conceitual da adição. Nesse caso, observamos um fato curioso caracterizado pelo aluno efetuar subtraendo menos minuendo em $(6-3=3)$ e minuendo menos subtraendo em $(9-1$ =8) na mesma operação. Qualquer que seja a operação, quaisquer que sejam os valores das parcelas, subtrai o menor do maior, número a número. Essa meta ou antecipação é oriunda da ideia de que é sempre necessário subtrair o menor do maior. Isso leva o aluno a utilizar a regra de subtrair o menor do maior ao executar sua ação de realizar a operação de subtração. Essa regra está baseada em conceitos em ato relacionados à operação de subtração, válida para o campo dos números naturais, que é aplicada para o campo dos números inteiros. Identificamos, também, os que somam qualquer que seja a operação. [...] Identificamos que houve alunos que lidaram com as operações e os números conforme algum mecanismo que lhes veio à mente e lhes produziu resultados. Ora subtraíram o valor menor do maior sem respeitar ordem alguma no minuendo, subtraendo ou parcelas, ora confundiam as operações em uma mesma conta.

[...] Outros erros foram identificados apontando que existem alunos que ainda não compreenderam o processo de agrupamento e as trocas necessárias para o registro algorítmico na ordem da dezena, embora estejam no $5^{\circ}$ ano do Ensino Fundamental.

[...] Para outro aluno, em $(93+16=09]$ houve a omissão do "1" para formar a centena na resposta, que está colocado acima do 9, na dezena. Parece que memorizou o procedimento da linguagem comum na escola, o "vai um", sem dar a ela um significado, por elementar que fosse. Também nesse exemplo ressalto a ausência de percepção lógica no resultado obtido. Como pode operar $(93+16)$ e aceitar 09 como resultado?

Fonte: Guérios e Daniel (2015, p. 11-12, 14).

O primeiro tipo de erro nos permitiu inferir as estratégias dos alunos no caso em que a retirada exige um empréstimo:

- Tratar cada algarismo como uma unidade isolada e, por essa razão, a subtração é realizada com esses algarismos isolados, pois no campo numérico dos naturais, essa operação só é possível pela retirada do menor do maior.

- Subtrair o algarismo menor do maior, alternadamente, não importando se o algarismo é do minuendo ou do subtraendo.

- Considerar os algarismos como unidades isoladas e não atribuir significação à operação de subtração e, por essa razão, ora subtrai esses algarismos, ora soma (quando essa retirada não 
é possível pelo fato de o subtraendo ser maior que o minuendo).

O teorema em ação que mobiliza essas formas de erro comum aparece em várias pesquisas (ZUNINO, 1995; PARRA, 1996). Eles sempre recorrem a tirar o menor do maior não importa a ordem das parcelas na operação.

A próxima reflexão refere-se aos cálculos $(869-46=403)$ e $(73+4=117)$.

Quadro 2: O cálculo $(869-46=403)$

[...] um aluno que subtraiu a unidade menor da maior, somou as dezenas, e subtraiu a dezena da centena porque o subtraendo é formado por 2 algarismos e o minuendo por 3 (na operação 869 - 46 $=823$ ). Ao realizar tal subtração $(8-4=4)$ revela não compreensão dos algoritmos tampouco de valor posicional. Opera conforme resultados estanques corretos que produz $(9-6=3),(6+4=10)$, embora tenha registrado apenas o zero e $(8-4=4)$, o que o levou a produzir o resultado 403 porque, separadamente os cálculos lhes foram corretos. Outra possibilidade foi ter efetuado $(9-6=3),(6-$ $6=0)$ e $(8-4=4)$.

Fonte: Guérios e Daniel (2015, p. 12)

A criança realiza uma operação de subtração e cria hipóteses a partir da significação atribuída aos algarismos dessa escrita. Essa significação não compreende o conhecimento da estrutura que está presente nesse tipo de registro (de base dez e posicional).

A mesma análise permite interpretar os procedimentos em que as crianças subtraem o menor do maior, não importando se o algarismo do registro é do minuendo ou do subtraendo. Nesse caso a criança trabalha com os algarismos dos numerais como se fossem algarismos justapostos, pois não atribui significação ao registro de representação do número. As antecipações compreendem regras de ação que explicitam conceitos em ato utilizados (a situação de subtração, nesse caso, que mobiliza o teorema em ação: retirar o menor do maior) e esquemas que dão conta de obtenção de resultados (a utilização do algoritmo que mobiliza teoremas em ação fragilizados que dificultam a compreensão da estrutura do Sistema de Numeração Decimal).

Essas inferências podem justificar também o caso em que a criança completa com um zero à direita em um numeral com menos algarismos para adicionar a outro com mais algarismos. A não significação aos registros de representação do número embasa as ações da criança que se apoiam no procedimento algoritmo, mecanizado, mas que lhe dá segurança para acreditar que obterá o resultado. Esse procedimento é realizado conforme orientações recebidas, isto é, colocar os algarismos um embaixo do outro e, nesse caso, o zero é acrescentado por não ter valor nenhum e por "preencher uma casa vazia".

Observemos o cálculo $(73+4=117)$. 
Quadro 3: O cálculo $(73+4=117)$

Um aluno somou indevidamente a unidade da $2^{\mathrm{a}}$ parcela com a dezena da $1^{\mathrm{a}}$ parcela considerando ambos como unidades $(7+4=11)$, registrou 11 e aceitou 117 como resultado da operação, que é 77.

Nesses dois exemplos, $(869-46)$ e $(73+4)$, temos em comum operações equivocadas $(8-$ $4=4)$, centena menos dezena e $(7+4=11)$ dezena mais unidade, evidenciando procedimentos incorretos no desenvolvimento de algoritmos. Identificamos um considerável número de ocorrência de erros devidos a não compreensão de valor posicional na estruturação da conta armada, visto que operam os algoritmos sem relacionar com os valores correspondentes das parcelas.

Uma possibilidade que não descartamos é o aluno ter utilizado o mecanismo do algorítmico da multiplicação para a resolução da adição. Nesse caso, em $(73+4=117)$ fez $(3+4=7)$ como se fosse $(3 \times 4)$ e $(7+4=11)$ como se fosse $(7 \times 4)$ no algoritmo da multiplicação.

Observamos que há alunos que não percebem a ausência lógica nos resultados que obtêm, e os aceitam; que tais resultados não causam desconforto, ou suspeita, que os levem a pensar sobre a operações que realizam e seus resultados; que não refletem sobre o resultado que obtêm e a operação que realizam. Esses dois exemplos, respectivamente $(869-46=403)$ e $(73+4=117)$, evidenciam o que afirmamos, uma vez que $(869-46=823)$ e $(73+4=77)$. Ora, se o aluno subtraiu 46 de 869 e obteve 403, significa que realizou a diferença de 466 e não de 46 para o resultado que obteve, pois $(869-466=403)$ e $(869-46=823)$. Ou seja, subtrai dezenas de um número e obtém resultado de subtração de centenas e não percebe. Em $(73-4=117)$ adiciona unidades a um certo número e obtém um resultado acrescido de centena, e não percebe.

Fonte: Guérios e Daniel (2015, p. 12-13)

Guérios e Daniel (2015) demonstraram-se perplexas não pelo fato de um aluno ao final do $5^{\circ}$ ano do Ensino Fundamental dividir 84 por 4 e encontrar 210 como resultado, mas sim, por aceitar com naturalidade o resultado. Para as autoras, o fato do aluno dividir 84 por um número qualquer e encontrar um resultado maior do que o interio que dividiu, tem significado expressivo quando pensamos na aprendizagem. Mesmo que equivocadamente multiplicasse 86 por 4, encontraria 336 como resultado, o que confirma o pressuposto de frágil aprendizagem, nesse caso.

Na solução apresentada podemos inferir as seguintes estratégias realizadas pelos alunos: Tratar cada algarismo do dividendo em função de seu valor absoluto (unidades) e não relativo e, por essa razão, erro da posição do resultado. Trabalhar com os outros algarismos do numeral adicionando-os (nesse caso não entende que está dividindo e pelo fato de dispor espacialmente conforme o algoritmo da adição esquece a operação que estava realizando.

Nesse caso os alunos demonstram pouca habilidade no domínio do algoritmo da divisão.

Que teorema em ação é comum a esse erro? Parece estar prevalecendo que quando aprendem a montar as continhas a professora fala "unidades embaixo de unidades e dezenas de dezenas, etc". Só que na divisão com um dividendo com dezenas, o primeiro resultado ou é dezena ou unidade dependendo do divisor. Isso muda a configuração da operação mas não o teorema em ação. Não atribuir significação aos quocientes obtidos com a divisão pode significar também a não compreensão de outras ideias da divisão. Esse resultado não poderia ser admitido se um conceito da divisão fosse evocado: Quantas vezes 4 unidades cabem em 84 unidades ou 
quantos grupos de 4 unidades posso fazer com 84 unidades.

Se essas ideias relacionadas à divisão estivessem de posse dos alunos, como conceitos em ato, as antecipações compreenderiam regras de ação que explicitariam esses conceitos em ato utilizados e possibilitariam esquemas que dariam conta de obtenção de resultados. Quando o aluno utiliza algoritmo mobilizando teoremas em ação fragilizados que dificultam a compreensão da estrutura do Sistema de Numeração Decimal os resultados encontrados também são desprovidos de significado.

Guérios e Daniel identificaram que erros de tabuada são frequentes nessas operações. Houve ocorrências em que acertavam o procedimento exigido pelo algoritmo, mas erravam a tabuada no processo resolutivo. Esse fato as levou a discutir sobre a pertinência, ou não, de os alunos conhecerem a tabuada, enfatizando que conhecer a tabuada não implica em decorar seus resultados. Assim se manifestaram:

Em que pesem os posicionamentos teóricos que consideram irrelevante e desnecessário os alunos memorizarem a tabuada, a falta de memorização de seus resultados ou do conhecimento de mecanismos para sua obtenção são responsáveis por um acentuado número de erros de cálculos, em contas armadas ou não, nos $4^{\circ}$ e $5^{\circ}$ anos do Ensino Fundamental. Certamente, em anos vindouros tais erros estarão mantidos, quando não perpetuados por toda a vida estudantil dos alunos (Guérios \& Daniel, 2015, p. 13).

A tabuada também envolve conceitos de adicionar grupos iguais: somar de dois em dois, de três em três, etc. Se esse conceito não for requisitado no momento da resolução da questão para aqueles que não sabem de cor a tabuada as regras em ação se apoiarão em procedimentos de memorização e levam ao erro.

O próximo exemplo refere-se ao cálculo $(77 \times 8=5)$, cujo procedimento demonstra equívoco resolutivo de natureza conceitual que remonta a conhecimentos elementares desde a construção da ideia de número. Se observarmos isoladamente a resolução, observamos que acertou o resultado de $(8 \times 7=56)$, no entanto colocou o 6 da unidade sobre o 7 da dezena e o 5 da dezena no lugar da unidade.

Quadro 4: $\mathrm{O}$ cálculo $(567 \times 6=3834)$

Um outro aluno apresenta um procedimento que mostra que ele, de fato, não compreendeu o algoritmo da multiplicação porque mantém o procedimento equivocado nas três intervenções necessárias ao cálculo. Em (567) X 6) inicialmente faz $(6 \times 7=42)$ colocando o 2 da unidade sobre o 6 da dezena e o 4 da dezena no lugar da unidade. Faz $(6$ X $6=36+2=38)$ e repete o procedimento incorreto ao colocar o 8 da dezena sobre o 5 da centena e o 3 da centena no lugar da dezena. Finaliza consolidando o equívoco ao fazer $(6$ X $5=30$ e $30+8=38)$. Assim, obtém o resultado de 3834 para a operação $(567$ X $6=3402)$. Interessante observar que, nesses exemplos, os alunos não erraram os resultados da tabuada quando a utilizaram. Erraram o procedimento algorítmico.

Fonte: Guérios e Daniel (2015, p. 14)

Tais regras de ação utilizadas pelo aluno são baseadas em antecipações que se apoiam 
em suas compreensões sobre a estrutura do Sistema de Numeração Decimal. Igualmente sobre procedimentos algoritmos mecanizados desprovidos de significação em se tratando de conceitos. Por essa razão tais antecipações o induzem a colocar os algarismos resultantes dos produtos obtidos em lugares errados, pois esses algarismos do numeral não são interpretados à luz da conceitualização da estrutura do SND. São conceitos em ato errados que sustentam suas inferências e culminam em suas formas de proceder.

Quadro 5: $O$ cálculo $(869-46=23)$

Já o erro cometido por um aluno na operação $(869$ - 46) que pode parecer distração porque calculou corretamente como parcelas individuais $(9-6=3)$ e $(6-4=2)$, se configura em ausência de conhecimento das operações aritméticas elementares pelo aluno ao final do $5^{\circ}$ ano do Ensino Fundamental. Para ele, se não havia algarismo para subtrair da centena 8, então não havia cálculo a fazer e zero significa a ausência de operação. Não compreendeu a operação como 869 unidades menos 46 unidades. Se houvesse compreendido, não responderia 23 como resultado da operação, que é $823(869-46=823)$. Também aqui o resultado obtido não foi desconfortável ao aluno pois subtraiu menos de uma centena (46) de mais de 8 centenas (869) e obteve apenas 23 unidades.

Fonte: Guérios e Daniel (2015, p. 14-15)

Novamente se configuram inferências que sustentam regras de ação baseadas em antecipações relacionadas à compreensão da estrutura do SND, isto é, à não conceitualização dessa estrutura e por essa razão conceitos em ato errôneos. Essas inferências não o auxiliam a interpretar o resultado obtido bastante aquém do esperado.

Importante evidenciar que o trabalho com estimativas e aproximações colabora para a atribuição de significação aos algarismos dos numerais que representam os números. No caso em questão o valor 869 poderia ser aproximado para um valor exato, por exemplo 860 e, da mesma forma o valor 46 para um valor aproximando 40. Os demais valores resultantes da decomposição poderiam ser operados separadamente e adicionados ao resultado da subtração entre 860 e $40,820+(9-6)=823$.

Esse trabalho com estimativas e aproximações pode ser inferido como importante, a partir do momento em que verificamos erros recorrentes como esses apresentados por nossos alunos ao longo da escolaridade.

Além das ocorrências citadas, encontramos situações curiosas cujos processos procedimentais foram, também, resultados de inferências realizadas que culminaram nas regras de ação às quais os alunos lançaram mão para resolver situações de divisão. Nesses procedimentos outros conceitos entraram em cena e esses dizem respeito à operação inversa da divisão que é a multiplicação. Outros conceitos em ato são exigidos, dentre eles o de reversibilidade. Se eu divido, para obter o resultado de uma divisão para retornar ao valor original devo multiplicar. O que falhou nesses procedimentos foram conceitos em ato relacionados à não memorizações de pequenas adições. 
As soluções de um mesmo aluno para os cálculos a seguir possibilitam reflexões acerca das tentativas realizadas.

Quadro 6: Os cálculos (99/16=9) e $(864 / 12=8)$

[...] percebemos a tentativa em encontrar o valor aproximado que multiplicado pelo divisor lhe permitisse encontrar o resultado correto. No entanto, o procedimento não se consolidou. Seus registros evidenciam que tentou resolver a divisão utilizando a multiplicação para (99/16) e para (864/12). Procurou o resultado da divisão construindo a tabuada relativa ao dividendo de cada uma delas (16 e 12) visto que utilizou o procedimento multiplicativo para construí-las e as escreveu, embora erre as multiplicações $(16 \times 2=21$ e não $32,16 \times 3=38$ e não $48,16 \times 5=50$ e não 80 e assim por diante). No início da análise desse dado, consideramos que o fato de "buscar a resolução na tabuada" significava que construía estratégias resolutivas fundamentadas em sua estrutura cognitiva e que escrevê-las era uma estratégia para "enxergar" o que precisava.

Com a continuidade da análise, conforme segue, percebemos que evocava procedimentos, sem que os compreendesse.

Na operação (864/12) iniciou pela tabuada do 12 e no terceiro cálculo passou para a tabuada do 13 sem que pudéssemos encontrar em seus registros uma justificativa para tal. Assim, o raciocínio do aluno, que em princípio nos fez pensar que tinha sentido, nos fez concluir tratar-se de uma tentativa vã. Além disso, errou as contas armadas da multiplicação. Entendemos que não compreendeu o sentido matemático da tabuada, pois sequer percebeu que os produtos obtidos não correspondem à tabuada. Em (99/16) apresentou 16, 21, 38, 42, 50, 53, 62, 88 e 90 como resultados, não observando que a diferença entre consequente e antecedente não é 16 . O mesmo ocorreu em (864/12) onde apresentou 39, 42, 55, 62, 72, 84 e 97 como resultados, não observando que a diferença entre consequente e antecedente não é 13, já que utilizou a tabuada do 13 na tentativa de solução. Em relação às contas armadas aqui em análise, observamos que em (99/16), transportou o 9 do resultado errado da multiplicação (16 $\times 9=90)$ provavelmente por ser o valor mais próximo de 99 . No entanto, faz $(16 \times 9=99)$ para obter resto zero.

Ainda em relação (864/12) observamos que transportou o 8 do resultado errado da multiplicação $(13 \times 8=84)$ provavelmente por ser o valor mais próximo de 86 em relação à 864 . No entanto, fez $(86-84=82)$ e apresentou como resto 824 .

Fonte: Guérios e Daniel (2015, p.14-15)

Diferentes conceitos e teoremas são colocados em ação caracterizando as regras de ação explicitadas por meio dos procedimentos apresentados nas resoluções das questões. Quando evocados, esses teoremas e conceitos em ato comandam as inferências realizadas: em algumas soluções essas inferências apoiaram-se no procedimento de partições (ao utilizar as tabuadas do 12 ou do 13). Esse procedimento explicitado permite identificar que o erro cometido foi relativo às mulitiplicações: 13 x $5=55$ e não 65 ou $16=3=38$ e não 48 . A compreensão dos erros apresentados é importnate para permitir ao professor a reorganização de sua práitca para levar esses alunos à superação das incompreensões reveladas nas regras de ação que comandaram as resoluções. Nesse caso é importante identificar que a partição do dividendo em quotas a partir do divisor é um procedimento correto que esbarra na multiplicação dos divisores por $2,3,4,5 \ldots$, até 9 . As inferências que guiaram as regras de ação que comandaram os procedimentos não estão erradas, mas apontam que as quotas não são garantidas, pois a diferença não se mantém: igual a 12 ou 16. Se a constância da difefrença fosse compreendida os erros das multiplicações poderiam ser corrigidos. Para o professor essa identificação é fundamental para levá-lo a organizar situações de divisão com o procedimento da partição em quotas. Isso significa levar os alunos a compreenderem que se a tabuada utilizando o divisor 
for utilizada para chegar ao resultado da divisão tem que compreender a diferença constante entre dois reultados consecutivos (sempre 12 ou sempre 16). Isso significa levá-los a corrgir erros cometidos por conta das multiplicações erradas ou das diferenças entre dois termos não mais constante. Nesse caso as regras de ação explicitadas em função das inferências estabelecidas ainda contemplam fragilidades conceituais que precisam ser trabalhadas pelo professor.

\section{Considerações finais}

Iniciamos essas considerações com as evidências de Guérios de Daniel (2015, p. 18) de que "grande parte dos erros cometidos por alunos ao final do $5^{\circ}$ ano em cálculos com as operações aritméticas por meio de algoritmos convencionais se deve a não compreensão dos conceitos matemáticos elementares desenvolvidos nos anos iniciais do Ensino Fundamental". As autoras trazem de Cury (2007, p. 19), que "ao analisar as respostas dos alunos, o fundamental não é o acerto ou o erro em si, mas as formas de apropriação de um determinado conhecimento, que pode indicar dificuldades de aprendizagem". Atentas a esta afirmação, Guérios e Daniel observaram, sobremaneira, a fragilidade do desenvolvimento do pensamento aditivo e do multiplicativo pela não percepção numérica dos resultados encontrados, pelo delineamento dos procedimentos realizados e pela ausência de sentido matemático manifesto nas atividades desenvolvidas. Para elas a "questão das dificuldades reveladas é de responsabilidade pedagógica" (2015, p. 19). Daí, porque engrossam a fileira dos pesquisadores preocupados com a formação inicial de professores, particularmente dos que atuam nos anos inicias do ensino fundamental, para o que, chamam atenção para Mindal e Guérios (2013) que, a partir da pesquisa brasileira realizada no período de 2006 a 2010, apresentam indicativos sobre a fragilidade da formação inicial de professores, pontuadamente nos Cursos de Pedagogia. Guérios e Daniel falam aos professores por meio de palavras de Pinto (2000) que diz que aprender é também saber de outro modo. Nesse caso, é "desenvolver modos de ensinar que transitem entre os acertos e os erros revelados pelos alunos em sala de aula" (Guérios e Daniel, 2015, p.19). Tendo em vista o exposto, repercutimos no presente artigo a indagação de Guérios e Daniel: "como é possível aceitar que alunos cheguem ao final do $5^{\circ}$ ano com dificuldades tão elementares como as aqui reveladas?" (p.19)

Tais constatações nos motivaram a refletir sobre o cenário configurado pelas dificuldades reveladas pelos alunos ao final do $5^{\circ}$ ano do Ensino Fundamental. Fizemos esta 
reflexão à luz da teoria dos campos conceituais de Vergnaud (1990), que permitiu focar nos conceitos e teoremas em ato utilizados oriundos de antecipações que sustentam regras de ação e inferências realizadas pelos alunos para a resolução das operações de adição, subtração, multiplicação e divisão com números naturais.

As análises permitiram explicitar a compreensão do SND pelos alunos, no momento da utilização dos algoritmos operatórios e desvelar as hipóteses que elas manifestavam, para justificar estratégias e procedimentos utilizados ao realizar essas operações. Ao proceder com análises subsidiadas pela teoria dos Campos Conceituais foi possível apontar o campo conceitual (conjunto de situações e conjunto de conceitos) necessário para a realização dessas operações.

Ao manipular os algoritmos os alunos lançaram mão dos mesmos esquemas (iniciar da direita para a esquerda para as adições, subtrações e multiplicações e da esquerda para a direita no caso das divisões), no entanto os erros eram decorrentes da não identificação da estrutura do SND na notação escrita. Por isso emprestavam ao subtrair uma unidade das dezenas (ou vice e versa) e a acrescentavam às unidades ou a elas justapunham, ou trabalhavam com o valor absoluto dos algarismos do numeral.

Teremos que investigar se os erros apresentados por nossas crianças são decorrentes da incompreensão da estrutura do SND, da incompreensão do algoritmo ou ainda, se os esquemas gerariam criações próprias que funcionariam se houvesse compreensão do SND.

Importante, nas intervenções, será considerar as produções dos alunos e evidenciar os esquemas utilizados e as atribuições de significados aos dígitos da notação numérica que levam a soluções diferentes. Isto deve ser feito aproveitando os argumentos utilizados e ao mesmo tempo socializando com os demais colegas da classe. São essas produções que podem subsidiar propostas de intervenção para superação de obstáculos (epistemológicos ou pedagógicos) e avanços conceituais.

Igualmente, e não menos importante, é a organização de um trabalho voltado para a compreensão da estrutura do Sistema de Numeração Decimal presente nos registros de representação utilizados para representar os números e a forma de organização dos diferentes registros: palavra (sufixos e prefixos) e notação escrita (valor absoluto e valor relativo dos algarismos).Parece-nos importante pensar em estratégias para desenvolvimento de habilidades relativas ao cálculo mental e à memorização de pequenas somas.

O esquema é um produto de ordem psicológica apoiado na representação mental. As produções escritas não são capazes de disponibilizar as construções amplas e complexas das 
crianças. É necessário, portanto, complementar os registros com justificativas e argumentos que revelem o que não se torna explícito.

Tal intencionalidade implica considerar a diversidade do pensamento humano na organização da prática educativa e, por essa razão, efetivar uma transposição didática do conhecimento científico produzido, não o levando como pronto e acabado, ao contemplar interesses, necessidades, dificuldades, intuições primeiras, possibilidades, abordagens, encaminhamentos, estratégias, entre outras questões.

Igualmente considerar a necessidade de uma forma diferenciada do olhar do professor em relação às produções das crianças buscando compreendê-las, aceitá-las quando corretas, mesmo que diferentes ou não canônicas, socializá-las para valorizar o sujeito epistêmico que é capaz de pensar e de produzir conhecimento, entendê-las enquanto frágeis ou oriundas de processos de desenvolvimento, e, colaborar para as rupturas necessárias por meio de desafios cognoscitivos e de problematizações.

Esse modo diferenciado de olhar implica rupturas pessoais oriundas de nossos processos de formação, tanto escolar como profissional, em cursos de formação de professores. Essas rupturas significarão desconstruções e reconstruções de natureza conceitual, procedimental e profissional, conforme apontado por Muniz (2009).

\section{Referências}

BRASIL, Ministério da Educação. Matrizes de Matemática do $5^{\circ}$ ano do Ensino Fundamental. (2015). Brasília: MEC, SEB, Inep, 2008. Disponível em: $<$ http://portal.inep.gov.br/web/saeb/matrizes-de- referencia-professor $>$. Acesso em: 15 mar.

CURY, H. M. (2007). Professora, eu só errei um sinal: como a aprendizagem de erros pode esclarecer problemas de aprendizagem. In: Disciplinas matemáticas em cursos superiores: Reflexões, relatos, propostas. Porto Alegre: EDIPUCRS. CURY, H. M. Análise de erros: o que podemos aprender com as respostas dos alunos. Belo Horizonte: Autêntica.

GATTI, B. A. (2010). Formação de professores no Brasil: características e problemas. Educação \& Sociedade, Campinas, v. 31, n. 113, p. 1.355-1.379.

GATTI, B. A. (2013). Educação, escola e formação de professores: políticas e impasses. Educar em Revista. Curitiba, n 50. P. 51-67.

GUÉRIOS, E.; DANIEL, J.E.S. (2015). Entre erros e acertos: revelações sobre a aprendizagem das operações aritméticas elementares de alunos dos anos iniciais do ensino fundamental. Natal: REMATEC, $\mathrm{n} * 20$, p. 6-20. 
GUÉRIOS, E. (2002). Espaços oficiais e intersticiais da formação docente: história de um grupo de professores na área de ciências e Matemática. 2002. Tese (Doutorado em Educação) - UNICAMP. Campinas.

KILPATRICK, J. (1996). Fincando estacas: Uma tentativa de demarcar a Educação Matemática como campo profissional e científico. In: ZETETIKÉ/UNICAMP, Faculdade de Educação, Revista do Círculo de Estudo, Memória e Pesquisa em Educação Matemática. v.4, n. 5, p. 99-120.

MINDAL, C.; GUÉRIOS, E. (2013). Formação de professores em instituições públicas de ensino superior no Brasil: diversidade de problemas, impasses, dilemas e pontos de tensão. In: Mindal e Guérios (Org.). Educar em Revista, Curitiba, Ed. UFPR, n. 50, p. 21-33.

MUNIZ, Cristiano A. B. \& BITTAR, Marilena. (2009). A aprendizagem matemática na perspectiva da teoria dos campos conceituais. 1. Ed. Curitiba: Editora CRV.

PINTO, N. B. (2000). O erro como estratégia didática: estudo do erro no ensino da matemática elementar. 2. ed. Campinas: Papiru.

VERGNAUD, G. (1990), Gérard. La théorie des champs conceptuels. Recherches em didactique de mathématiques, v. 10, n. 23, 1990, p.133-170.

Submetido em : 30/05/2019

Aceito em : 18/06/2019 